\title{
FAUNA CADAVERICA BRASILEIRA
}

\author{
Conferencia realisada pelo Prof. O. Freire, em 1921, no \\ Centro Academico "Oswaldo Cruz" \\ (Continuação e fim)
}

O cotejo demonstra-nos que não são muitas as especies cosmopolitas, que, em geral, as especies que occorrem no Brasil não são as mesmas européas, que muitos generos européus faltam entre nós emquanto que muitos gene:'os nossos faltam nas faunas européas. Era assim de sc esprar. Mas tem-se agora baseado na observação a prova do fundamento dessa suppesição. Mas, por divergir a lista, não estava derruilo o systema. O importante seria no caso estudar a ecologia, isto é, os habitos, os costumes dos insectos, e a sua biologia, isto é. o tempo e o modo das suas metamorphoses. O problema que loga se apresenta nessa segunda parte dos estudos da fauna do ponto de vista medico-legal \& o do praso que levam os insectos e acarianos para a destruição completa dos corpcs. Realmente, o fim do estudo faunistico é a determinação chronologica. Os quadros de turmas se situam dentro de um determinado praso que Mégnin avaliou no minimo de 2 ao maximo de 4 annos. Si esse praso sie alargar, com elle se alargará o tempo das tưrmas e. correlatamentc, se accentuará a facilidade de distinç̧ão entre os varios grupos. Si ao contrarı ( praso total se encurtar, mais breve serão as divisões, e dest'arte menos precisos os limites, mais facil o tunuulto, menos provavel a distincção. Justanıcnte um dos abalos grandes que soffreu a doutrina de Megnin, promanou das observações de um medico polaco, de nome arrevesado, Niezabitowski que observou destruirem os inscctos cadaveres de fetos e de recem-nascidos no praso de 14 dias no verăo, emquanto que em corpos do mesmo tamanho, Mégnin só vira a destruição em periodo de mais de um anno. E' verdade que Mégnin abservou cadaveres que se achávam, via de regra, no interior de casas, sob telleiros e raramente, bem raramente, ac ar livre. E' muito difficil fixar em numeros exactos o praso de destruição dos corpos pelos insectos. $\mathrm{Na}$ Bahia, no verão, quando a vida dus insectos é intensa, exuberante, ohesrvei a destruição total de cadavares de 
fétos, de recem-nascidos, de pesa variavel entre $21 / 2$ a 4 kgs., em prasos bem proximos dos de Niezabitoviski e ás vezes bem men:ores, em 12 e até em 6 dias. Ainda a 9 de Janeiro de 1914, expurha eu junto ao galpão do Instituto Nina Rodrigues da Bahia e corpo de um recem-nascido de 2.900 grs. para demonstrar ao meu collega professor Pirajá da Silva alguns factos referentes à vida dos insectos. Pois bem, a 15 do mesmo mez, no caixote que continha o pequeno corpo só havia ossos e residuos dessecados, tendo neste trabalho apenas collaborado moscas, larvas e coleopteros.

E' porém perigoso generalisar taes observações, tanto quanto é difficil fazer eguaes experiencias em cadaveres de maior volume, particularmente da adultos Não preciso explicar porque nunca pude tentar nem pośso esperar praticar ainda a observaçãc de deixar o cadaver de um adulto pára ser totalmente destruido só pelos insectos. Si escapasse das garras da policia, nĩo fugiria, de certo, á fama de feiticeiro. Mas, pelo que vi, nas numerosas observações que fïz em cadaveres humanos e em cadaveres 'de animaes, por inumeras razões que a experiencia me ensinou e que seria fastidioso recordar aqui uma por uma, tenho que os prasos de Mégnin são exagerados. A só acção dos insectos é capaz de esqueletizar um cadaver de adulto em 4 e 6 mezes, tal seja a riqueza entomologica, do local, taes sejam as condiçôes de temperatura. Na mór parte dos casos, até nos cadaveres expostos, a destruição póde ser muito mais rapida, pois collaboram co mos pequenos insectos o asqueroso e impertinente urubú e os ratos assiduos. Tambem si a riqueza do local em insectos não é grande, factores varios podem dilatar mais esse praso: o frio entorpecendo tanto a putrefacção quarto a actividade dos insectos, a seccura do ar e as altas temperaturas, favorecendo a evaporação e, dest'arte tornando frequente a múmificação dó corpo.

Em certas zonas do nordeste, ha até facto curioso, nos areiaes extensos nos taboleiros nos descampados, sob a canicula, depois de um periodo de putrefacção intensissima, a evaporação provoca mumificação facil de certas partes do corpo.

Os insectos frequentadores da phase putrida da decomposição somem-șe, nias na época das chuvas, muitas vezes enxarcado o corpo, novamente se vî a putrefacção e, som e!lia, retornam insectos que haviam desapparecido. Seja como for, na maioria dos casos, a acção destruidora dos insectos se processa em praso muito mais curto do que penou Mégnin, mormente si são abundantes, as moscas, entre as quaes no Brasil incontestavelmente a que tem parte leonina é a conhecida varejeira, a Csrysomyia macellaria que os clinicos tanta vez teem visto produzindo myiases.

Já o encurtamento do praso de destruição total, faz desconfiar da facilidade de utilização do eschema de Mégnin, porque reduzindo-se o temp? dos periodos, crescem as probabilidedes de confusão e baiburdia entre os trequentadores pelo menos das phases mais proximas. O fulcro, porém, 
da questão era verificar si havia como Mégnin affirmára e, con elle, tantos ohservadores, ordem fixa; constante, e quasi immutavel como concediam alguns. Existirá seriação, de facto, nos insectos que vão aos cadlaveres? Essa seriação è regular, constante, quasi immutavel? A conwição que tenho no particular de referencias a esses dous pontos, tem por si um unico merecimento, esteia-se num elemento que póde dar alguma autoridade, o tempo longo de experiencia trabalhosa de observação continuada. Não vos contarei por miudo a muita canseira que me deu - adquirir uma opinião propria, as longas horas de observação perdidas r.o ambiente da carniça acompanhando o movimento, a vida daquelles pequeninos seres que ali estavam realisando um dos mais admiraveis phenomenos que a natureza nos apresenta.

As observações, umas, foram espontaneas, outras, mais numerosas, poir mim provocadas, collocando pequenos corpos humanos, ou fragmentos de cadaveres humanos ou cadaveres de varias especies animaes, inteiros ou espostejados, ao ar livre, no campo, na oidade, no interior ou fóra das habitações, conforme o problema que no momento visava averiguar. Entre os perseguidores ou inimigos que me perturbaram esses estudos estavam os animaes insectivoros, principalmente as aves que podem representar papel importante do ponto de vista medico-legal. As aves insectivoras, mais do que as formigas $\mathrm{e}$ os bezouros predatorios, diziam as larvas e os insectos adiltos, por vezes limpam a seva, depois de largo tempo de anciedade e espera, dias a fio o corpo exposto em plena fermentação putrida, e o ọbservador verifica sempre ausencia completa e absoluta de insectos. E' que o seu concorrente mais habil e mais agil de trabalho, comem todos os habitantes da carniça. No Norte, a esquiva e encantadora lavarleira, Fluvicula clamyzura, é a mais inmpertinente, a mais assidua. Dizem que aqui não the fica atraz o civilisado ticotico, camarada traiçoeiro que nos destróe tanta observação bem começada e impossivel de reencetar.

Ass:gnalo o facto, porque é preciso attender que um cadaver pode não conter larvas de insectos, simplesmente porque aves insectivoras o limparam, como tive occasião de presenciar. E' uma causa de erro que o medico-legista deve investigar nas suas observações.

A primeira impressão que tive dos meus estudos, foi de que, sendo entre nós a putrefacção tumultuaria, não tendo o isochronismo que se suppunha nos tempos de Mégnin, na frequencia dos insectos tudo era balburdia e anarchia. Com o tempo, foi-se a impressão attenuando. $\mathrm{O}$ tumero maior de observações foi ccrrigindo cssa impressão primeira que ainda vagamente se percebe, no trabalho que sobre o assumpto pubi:quei em 1914. Estou convencido que, grossomcdo, o principio de Mégnin é verdadeiru. Ha certa ordem, certa seriação, no modo po- que os insectos vão aos cadaveres. O erro está em que essa ordem é apenas frequente, será ordem preferencial, nunca, fixa, constante, immutavel, ao 
contrartio, numerosas e faceis são as excepções. Dest'arte distinguir turma de traba!hadiores por periodos é eschematização demasiada que maiores factos não comportam. Na mór parte das observações o que eu notavá tendo em vista periodos mais longos da decomposição cadaverica poderá ser resumido da maneira seguinte em ondem que bem differe da de Mégnin como dos seus continuadores.

Logo idepois ida morte só frequentam os corpos as moscas e ainda assim essa frequencia mais parece producto dos seus habitos irrequietos do que da attracção particular que o corpo sobre ellas exerça. No interior das casas, são a mosca domestica, a Synthesiomyia que com ella vulgarmente se confunde e a mosca des estabulos. No campo, mais frequentemente as Sarcophagas e as auriverdes Lucilias e Chryzomyiası O odor da putrefacção se intensifica e á proporçâo quc augmenta, já esvoaçam em torno do corpo e o procuram, menos frequente a mosca domestica e a dos estabulos, copiosas as Sarcophagas, Chryzomyias, Syntheziomiyas e Lucilias Quando esse odôr é bem accentuado, do $2 .^{\circ}$ para $03 .^{\circ}$ dia por diantz surgem as escuras Ophyras ageis de vôo e de attitude tão caracteristica. Com os dias crescem de numero para decrescerem rapidamente. Só, geralmente um pouco mais tarde veem os coleopteros. Parece que o seu poder olfactivo não é tão grande com o das moscas.

Em geral primeiro vêm as Silphas, os Hister e os Saprinus negros e ás vezes formosas e delicadas Necrobias. Muito mais tarde, quando a carniça só é supportavel por quem tenha bom estomago ou heroismo facil é que surgem os outros bezouros, Lamblicoridas, Staphylinides e Desmestides. Progride o deliquio putrido, escorre a sanie, o corpo é um fervilhar de larvas de moscas, dando a impressầo de um liquido esipesso e vivo como nol-o representou Baudelaire nas conhecidas estrophes da Charaugne.

As larvas de gerações varias, as mais velhas, procuram já terreno apropriado á metamorphose. Umas fogem do cadaver, e na terra em volta, nos detrictos circumdantes formam as pupas.

O trabalho dosi colopteros intenso se faz então sob os corpos. Levantando-se estes ou revolvendo-se a terra subjacente encontram-se, é facil encontra-los em varias phases e em formas diversas de trabalho. O deliquio se accentua, os ossos se descobrem, o conpo já é uma putrillagem humida que no fundo se deposita e progressivamente se desseca, desprende un cheiro particular que o povo agudamente diz que não é cheino, que é murrinha, que se entraiha e persegue o observador por vario tempo.

Somem-se as moscası e dos bezouros os Lamblicornidae; escasseam as Silphas, os Hister os Saprinus, mas persistem as Necrobia e os Dermester. Comeşa a phase dos acarianos, apparecem de novo as baratas e as formigas predatorias e amantes de residuos seccos. Veem entãol os primeiros lepidopteros. Secca então de todo a carcassa e só se veem acaria- 
nos, borboletas e baratas. Consumatse a destruição. Mas essa ordem relativa que acabo de vos apresentar soffre excepções frequentisssimas, taes e tantas, que annullam de todo o seu valor. Pude indagar e reconhecer por miudo as causas principaes que as condiccionam e que, para mim são as seguintes:

1. $\left.{ }^{\circ}\right)$ Não ha exclusivismo do insecto para cada phase da putrefacção.

$2^{\circ}$ ) E' factor de importancia a concorrencia vital entre os necrophagos.

3." Influe na sua prsença ou na sua ausencia a rtiqueza em especies e genero da região, a distribuição topographica.

4..$\left.^{\circ}\right)$ Não ha isochronismo dos periodos da decomposição cadaverica.

5. ${ }^{\circ}$ ) Uma chronologia precisa é impossivel.

Documentando agora.

Que o exclusivismo de frequencia do insecto em cada periodo da decomposição não existe é cousa facil de comprehender. $O$ insecto tem de facto preferencia por uma determinada condição chimica, por uma qualiciade de aúimento, mas si este escasseia ou desapparece, premido pela fome ou urgido pela necessidade de postura, abandona as suas predilecções e recorre ao que de melhor encontra. Necrophagia obrigatoria é cousa que, me parece, não existe em rigor. A necrophagia é prefenrencial, mas se o cadaver falta, o insecto recorre a outras substancias em decomposição, excrementos, materias animaes ou vegetaes.

E si entre substancias de tão diversas constituição é possivel extender-se a éscolha. quanto mais nas varias phases. mais ou menos proximas da decomposição em que a materia prima é a mesma. A mosca varejeira, a Chrysomyia, cuja larva é habitulamente necrophaga, prefere para postura os cadaveres em plena putrefacção gazosa ou no começo ldellia, mas frequentam cadaveres recentes e ate põem em individuos vivos, como en plena putrefacção qualiquativa. O mesmo se passa cmo as Sarchoplagas como pude cer. Nem é indifferente o que se passa com as Sytheriomyias e oom as Lucilias, como pude verificar.

Os Demester preferem visivelmente o fim da putrefacção e os residıos, dessecados. Mas eu os surprehendi mais de uma vez em flagrante delicto na putrefacção gazosa. Poderia trazer-vos centenas de exemplos como estes a demonstrarem que especies collocaldas numa determinada turma de trabalhadores da morte frequentam tambem os cadaveres em outros periodos com certa assiruidade.

Um ponto, sobre o qual nem um observador insistiu, que me parece importante nos estudos da seriação, é a concorrencia vital entre os insectos. A natureza chimica do meio os atrahe de facto, mas as possibilidades do seu desenvolvimento dependem da existencia de outras especies que as precederam, o seu lugar póde estar occupado por outro e este outro melhot dotado pode expellil-o. Quando as grandes Silphas apparecerem em avultado numero não rano os modestos Hister e Saprinus se somem, para reapparecer ás vezes quando aquellas, por qualquer motivo desapparecerem. 
Si numa cultura de moscas domesticas, permittirmus a postura das larviparas Sarcophagas ou da Syntheziomya verificaremos em geral com espanto que essas medram emquanto as outras desapparecem.

A mosca domestica que nas primerras horas depois da morte é senhora do terreno continúa a visitar o corpo emquanto outras especies como as Sarcophagas não se mostram e á proporção que estas crescem ellas se somem e se faitam ellas augmentam de numero. Vê-se, pois, que a concorrencia vital pode supprimir especies, generos e até giupos na seriação de sorte a não encontrar o perito seus vestigios. Outrá condição muito importante segundo meu pensar é a distribuição topographica dos insectos na região. Especies existentes numa cidade não se mostram em egual numero em toda a parte e até nem em toda a parte se mostram. No laboratorio idaSanta Casa, são numenosissimas as Sarcophagas. mas no Matadouro Municipal onde ha mosica domestica, Syntheziomyia, Lucilia e até Chryzomyia, nem eu nem Belfort de Mattos encontramos uma só Sitricophaga.

Com os coleopteros, bezouros, ainda este facto é mais expressivo. Passaram-se experiencias e experiencias, num lugar, sem que nunca eu encontrasse determitadas especies e até genros, como s deu com os Dermester, as Necrobias e as Silphas. Na maceração do Gabinete de Anatimia da Faculdade, pullulam as Silphas, mas faltam as Necrobias que em outras yontos da cidade sầo abundlantes.

$\mathrm{O}$ insecto ou o genero ou o grupo pode faltar num determinado caso porque é poucc frequente naquelle ponto e assim a distribuição topographica altera a seriaçăo. Não precisarei insistir na falta de isochr'onismo dos periodos putrefactivos. A marcha da decomposição depende de tantos factores intrinsecos ao cadaver ou concernentes ao meio, do modo e da intensidade da infestação microbiana, da sua natureza, da facilidade ou da difficuldade do seu desenvolvimento ou de sua generalisação, das influencias reciprocas dos productos da propria actividade microbiana, da evaporação, do calor, da humidade ambiente, emfim de causas multiplas e varialda .

Aquelle velho escherma de Casper foi, a meu vêr, uma esperança que falhuu.

O problema da chronologia putrefactiva ainda hoje, 90 annos depois, pode ser considerado superior ás forças humanas, como no tempo de Orfila.

Não tem limites nem qualificativos a minha admiração, só egual ao meu espanto, quando vejo medicos legistas, de olhar magistral e experiencia larga, distribuirem a mancheias com precisão diagnosticos exactos do tempo da morte pela chronologia da decomposição.

$\mathrm{Na}$ minha humildade, os respeito. Si fosse juiz, na minha ignorancia (c) temeria. O que a experienoia me ensinou é differente, embora seja bem pouco o que eu consegui saber de tudo, em tudo e por tudo. 
A miude se observam na pratica, no mesmo cadaver simultaneamen:e varios periodos putrefactivos nas diversas regiões do conpo; umas mumificardas, ontras no deliquio putridio, outras no final da putrefacção butyrica e caseica. Os typos de fermentação, que Mégnin descreved, gazosa, butirica, caseica, saponificação, ammoniacal, existem evidentemente, mas não são distinctas no tempo e muitas vezes são simultaneas no mes. no corpo e em regiões diversas.

Vê-se, pois, a impossibilidade de apertar a ordem de frequencia dos insectos nas lindes de um eschema, na angustia de uma chrınologia, mesmo admittindo larga toierancia no assignalar os prasos de duração de cada periodo. A esperança de uso facil do eschema e do conseyuente diagnostico chronologico pela chave que o mesmo fornece allúe peio alicerce, desmonona de todo.

A consideração de que o insecto páde frequentar cadaveres em perìodos varios e nelles fazer postura torna pouco aconselhavel e perigosa qualquer deducção do tempo pelo numero de geraçôes avaliado pella quantidade dos residuos de insectos encontraidos. A base do calculu era a possibilidade de só se dar o postura num unico periodo. Si as contaminações posteriores novas se podem dar, nunca se poderá saber si os insectos provêm todos de gerações sucessivas da mesma estirpe ou si de estirpes novas. Nada vale.

Mégnin valeu-se tambem da infuencia das estações. $N_{0}$ inverno paralysa-se a vida dus insectios, mas a putrefacção continúa, nas estações quentes os insectos retornam. Inutilizada a seriação que permittiria deduzir que a phase correspondente ios insectos que faltam se passou in inverno, todo o systema só se póde applicar ás moscas que primeiro frequentam os cadaveres, como muito bem fez ver Filomusi-Guelfi. No Norte qualquer deducção nesse sentido é impossivel. Nos mezes mais frios e chuvosos do anno, na diminuição. mas nunca ha falta de insectos. Sobre os te!heiros, no interior das rasas, nos luganes protegidos, no campo, como nas cidades, existem, embora menos abundantes.

Não ha falta. pois. e a quantidade dapendente de tantas circumstancias nunca poderá basear um diagnostico. Em São Paulo, porém, e nas reigões mais frias, o que observei leva-me a admittir que no caso está um pequeno prestimo da fauna cadaverica. A presença de insectos numerosos nunca servirá para fazer nenhuma deducção do tempo. A ausencia porém, completa, pode servir para um diagnostico ou para corroborar uma dignose feita com outros elementos de probab:lidade. Nos mezes frios ha parada completa da actividade dos insectos. O cadaver permanece longos dias sem elles, exposto no campo. No interior das casas só quando a temperatura baixa muito como o observei em 1918.

Imaginai ") encontro de um cadaver sem uma larva de mosca logo depois de um grande periodo de frio intenso. Sio facto se der em zona rica de moscas normaimente, podenıs affirmar com segurança que a morte 
não se deu antes que o periodo de frio se iniciasse, senão a presença de larvas seria certa. Ha causas de erıo que é preoisa evitar. Uma é relativa á distribuição topographica dư insectos. Mas ao lado destes outra avulta de importancia ainda maior: as variações thermicas diarias. Cscillando em limites muito vastos a curva thermica diaria entre nos, tenho observado em dias de frio mais de uma vez que a temperautra sobe tanto que permitte voltarem os insectos á relativa actividade nesse momento. Deve pois o perito ter em conta esse factor e examinal-o quando tiver de usar o elemento diagnostico a que estou aludindo.

Mas então direis, de noda vale a fauna cadaverica na diagnose do tempo da morte? E eu vos responderei que, ao contrario, ella póde valer em certos casos muito, tendo-se em conta o tempo da metamorphose dos insectos. E' esse a meu ver o maior prestimo da fauna cadaverica do ponto de vista medico-legal. Bem applicado pode prestar serviços de inestimaveis valias numa questão como esta do diagnostico do tempo da morte em que os recursos seguros á disposição do perito attingem á quasi miseria. Um exemplo vos dirá claramente.

Encontrado um corpo em plena putrefacção gazosa. Nelle existem numerosas pupas ou crysallidas de uma mosca, da Sarcophaga chrysostoma por exemplo, já toda's abertas. Pelos estudos de biologia da mosca sei que nas condições de temperatura ambiente nunca ella evolve em menos cie 28 dias. Si eu encontro a pupa aberta é que com certeza 28 idias se passaram depois da postura das larvas e pois, pelo menos, ha 28 idias está o cadaver em condições de ser frequentado pela mosca e consequentemente de não menos de 28 dias da data da morte. Este methodo porém está sijeito a erros e demanda como preliminares estudos regionaes bem feitos. Dos meus estudos pude concluir que três são as condições que acceleram ou retardam o periodo da evolução das moscas e dos bezouros. Riqueza ou pobreza nutritiva do meio, temperatura e humidade ambiente, sendo cstas as da maior influencia. Todo o mundo sabe que nas varias regiões de um paiz, o praso de evolução de um insecto varia. Essa mosca a que alludi, a Sarcophaga Chrysostoma, evolve em S. Paulo entre 28 a 40 dias emquanto que na Bahia, como observei evolve no praso de 13 a 32 dias. Para ser util por consequencia, a fauna cadaverica á medicina legal nas determinaçc̃es do tempo da morte, é indispensavel fazer minuciosos e completos estudos regionares năo só quanto á distribuição dos insectos nus tambem e principalmente scbre a sua biologia.

Foi por essa razão que, em bòa hora, suggeri a Belfort de Mattos fazer o esturdo das moscas do geneno Sarcophaga. E por isso que appello para vossa bôa vontade na espetrança de que possaes trazer tambem aiguma contrihuição a esse utilisș̣mo estudo. Já tive oocasião de applicar esse prestimo do estudo da fauna cadaverica na determinação da data da morte e o resuitado obtido é que me anima, ainda agora, a aconselhar o seu cmprego aos que se dedicam a trabalhos de thanatologia forense. 
Para aquilatardes bem, ademais, da valila do methodo diagnostico cumprirá attetnderdes que não possue como já vos disse no particular o medico legista recursos fartos, faceis e segurlos.

Até agora vos apontei apenas um dos problemas medioo-legacs que se pretendeu resolver com o estudo da fauna. E' o mais importante, o mais difficil, o problema basico, mas não é o unico. As promesass feitas á Medicina Legal com o estudo da fauna cadaverica são promessas iargas. Infelizmente, a realidade não acompanhou a ambição. Um dos outros problemas é a determinaçäo do local da morte, no caso de ser o corpo transportado de um lugar para outro afim de desviar a attenção e desnortear a actividade da justiça. Veiu a idéa do proprio Mégnin que, certa vez, affirmou que o pequeno corpo de uma criança encontrado no interior de um pacote em uma estação ferro-viaria de Paris proviera do meio-dia de França, porque só nessa região havia temperatura sufficiente para permittir naquelle momento o desenvolvimento de insectos.

$\mathrm{O}$ problema é mais complexos. Preciso é distinguir o transporte entre regiōes mais afastadas de um continente para outro de um paiz para outro ou entre regiões mais proximas. Tambem ha a considerar a possibilidade do transporte na mesma região, do campo para a cidade, ou da cidade para o campo, e ainda o transporte do interior apra o exterior da habitação ou vice-versa.

Quando se dá o transporte entre regiões afastadas, o diagnostico do local, de origem pela fauna é possivel quando as 2 regiões, a de origem e a em que foi achado o corpo, tiverem fauna cadaverica diversa, isto é, as moscas e os bezouros embora sendo dos mesmos generos porém de especies differentes.

Como vedes, tal deducçăo porém demanda um saber entomologico notave1 e conhecimento profundo da distincção geognaphica de cada especie, Mesmo admittindo esse saber verdadeiramente singular e raro é preoiso considerar em certas causas de erros faceis. A 1. ${ }^{\text {a }}$ é a da existencia de especies cosmopolitas, os bezouros Necrobia, Dermestes, a mosca domestica, a dos estabulos, etc., que encontrei no Brasil e existe na Europa, nos Estados Unidos, estão disseminadas no mundo inteiro. Maior, penigo do que este, de especie conhecidamente cosmopolita é a da existencia de outras a que se attribue muita vez restricta distribuição regular e que estudos posteriores vão mostrando que occùplam area muito maior do que era dado suppor.

Brauer e Bergst descreveram de exemplares vindos do Brasil uma especie de mosca a que denominaram Synthesiomya Brasiliana. Pois bem, essa especie brasiliana tem sido descripta em tantos lugares que não ha muito Bezzi a chamava mosca de disseminação mundial" O outro grande perigo é o da synonymia.

E' gloria desejavel até porque năo é facil. E em entomologia a gloria mais accessivel está em ser padrinho de baptismo de um insecto desco- 
nhecido. Criar uma especie nova é a aspiração de todos que cuitivam esse ramo de Historia Natural principalmente como veteranos. Dahi uma certa incontinencia na creação de especies, uma relativa precipitação, sómente desculpavel, porque como vos disse muitas vezes as descripções primeiras, typos, não cão sufficientemente claras e minuciosas. Assim muitas vezes a mesma mosca, o mesmo bezouro recebe em localidades diversas nomes differentes e só n.ais tarde quando lalguem tem a veintura de exantinar a collecção typo de cada descripção se vem a conhecer que todas áquellas especies novas se reduziriam muitas: vezes a um só insecto bem conhecido.

Giglio Tos verificou que a conhecida varejeira dos nossos climas Chrysomyia Macellaria recebeu 21 nomes diversos, sendo o que é maisı curioso além disso classificada como especies differentes em seis generos varios. Ainda ha mais e melhor, Sourcouf diz que a conhecida varejeira européa Lucilia Cesar recebeu 93 nomes differentes. Pois bem, desse, .78 eram devidos a um dipterologo que de uma só especie fez sem razão 78 diversas.

Assim póde a mesma especie existir em 2 lugares e o entomologista ignorar o facto porque o nome especifico diverge. Podendo afastar essas causas de erro ou, pelo menos, fazendo as reservas e restricções que ellas impõem é preferivel uma resposta do entomologista de certo valor para a Medicina Legal Ainda assim năo creio provavel se possa afłirmar com rigor o paiz de origem. $\mathrm{O}$ que me parece de maior possibilidade é affirmar com rigor se a morte se deu no nosso paiz ou no estrangeiro.

Esse serviço que o estudo da fauna presta como comprehendeis não é grande. Reputo difficilima a possibilidade mesmo, no caso de um pequeno cadaver de féto ou de recem-nascido entre regiões tão afastdaas.

De qualquer sorte o que nos interessava averiguar era a determinação do transporte entre os varios estados brasileiros. E' um terreno incerto, duvidoso, porque, como sabeis, além de não haver obras geraes o estudo da nossa fauna entomologica particularmente da fauna cadaverica está no estado embryonario. Do que a minha experiencia me ensinou nenhuma deducção se póde tirar a respeito porque as especies que encontrei na Bahia foram as mesmas que enoontrei em São Paulo, no Rio, em Minas e no Ceará. Differenças de quantidade, ausencia de uma ou outra especie explicavel pela ausencia de estúdos sufficientes em cada localidade e mais nada. Mégnin firmado em que ha especies de insectos ruraes e especies urbanas pretendeu deduzir da presença dellas o transporte do corpo. A existencia de especies de prdominancia rural e de predominancia urbana é incontestavel, mas a deducção de Mégnin é falsa, porque as especies ruraes podem frequentar a cidade e se encontram como observei mesmo no interior das casas pelo menos entre nós. E' preciso ter em vista que geralmente as cidades estão situadas em pontos até onde alcança o vôo pelo menos das moscas e essas possibilidades inutilizam a segúrança da 
deducção que na melhor hypothese poderiam valer como um vago indicio no caso do encontro por exemplo de insectos de mattas em cadaveres numa cidade ou vice-versa. A outra hypothese de determinação do transporte do interio: para o exterior das habitações è uma utopia. Como observei entre nós, as especies de dipteros e de coleopteros, necrophagos frequentam ir.differentemente os corpos no interior das casas ou fóra dellas. Quanto muito ha differença de quantidade. O odôr da putrefacção quando se intensifica chama para o interior das habitações especies que vivem fóra e as especies domesticas por sua vez se encontram tambem fóra das casas. Como vêdes a valia do methodo entomologico é bem pequeno. Um outro ponto que levantou seria disputa foi o da possibilidade de encontrando-se restos irreconheciveis ide fragmentos de $1 \mathrm{um}$ cadaver determinartse a especie animal pela natureza da fauna. O fundamento da hypothese era c'e que a fauna variava com a especie animal havendo insectos de frequencia peculiar a cada uma. Pude fazer no caso investigação que reputo c'ecisiva.

No curso dos meus trabalhos, consegui examinar insectos encontrados em corpos de 57 especie sdifferentes de animaes, mamiferos, aves, peixes: reptis e até vermes. Nunca vi a fauna divergir nem jamais encontrei uma só aspecie peculiar. Não terei coragem de vos apresentar a tahelia dos animaes em que pudie abservar. Seria fastidiosa a lista que por ser de bichos é bem piossivel que parecesse encerrar sugestões para jogos de azar. A meu ver de nada vale a fauna em semelhante scasos.

Outra determinação que se pretendeu fazer com o estudo da fauna deduzir se a morte foi repentina ou agonica - representa uma idéa infeliz de Delorme, a qual pecca pela propria base. Firmado em que certas especies de moscas não fazem postura nos individuos em plena saúde, da sua presença no corpo deduz a presumpção da morte agonica, da sua ausencia a de morte repentina. Delorme esqueceu que pode haver myiases em individuos em plena saúde e de punjante vitalidade. Tambem não quiz atender a que a postura dessas especies pode se dar em qualquer caso immediatamente depois da morte. Uma observação minha que fecha a questão: Certa vez no Mercado Modelo da Bahia um individuo de boa saúde apparente e de optimo desenvolvimento physico cáe fulminado for uma syncope em virtude de insufficiencia aortica que passara despercebida. Communicado o facto ao Instituto Nina Rodrigues comparece para o transporte do corpo o academico de serviço, que verififica com espanto antes de decorridas 2 horas depois da morte existirem nas narinas e nas commissuras palpebraes do individuo cumulos de ovos da varejeira (Chrysomyia) muito abundante no local. A morte era subita e, entretanto, a quantidade de larvas que dentro de 24 horas se encontravam era considerabilissima.

Para terminar a aborrecida exposição com que venho remindo os peccados que por acaso commettestes, purgando-os aqui mesmo graça á 
gentileza e á minha impiedade restava dizer-vos alguma cousa sobre a fauna dos tumulos cujo valor Medico Legal me pareceu dimniuto, senão absolutamente inutil.
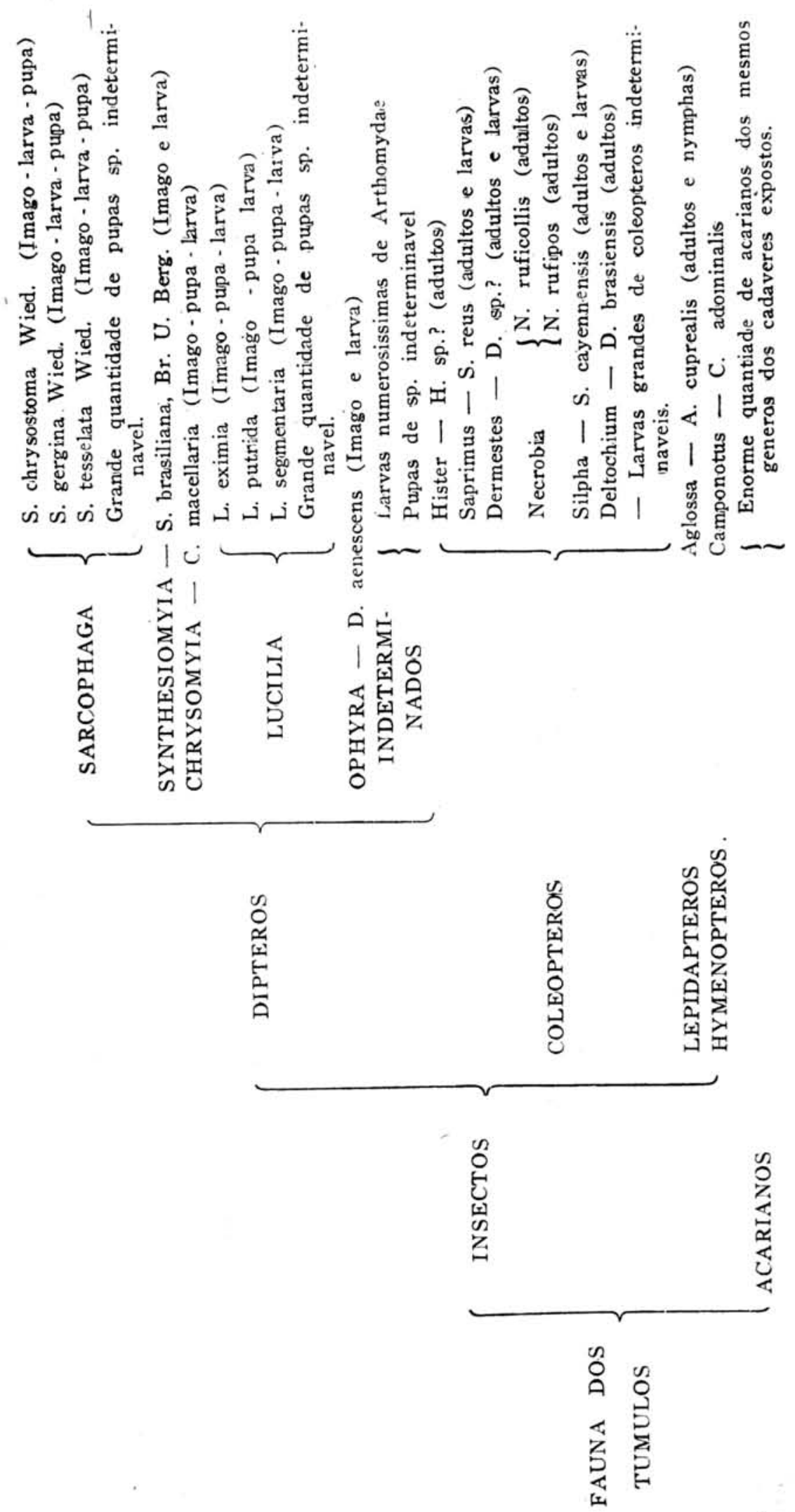
Procurei tambem estudar o modo por que os insectos vão ter aos corpos inhumados. Pude verificar que nos carneiros e nos tumulos uma verdadeira fauna se conserva exuberante nos intervalos entre uma inhumação e a immediata.

Dos dipteros pude verificar que a contaminação se dá geralmente antes da morte, mas é força confessar que não encontrei explicação para sua existencia em ccrtos casos em que essa contaminação não podia ser invocada. Vi é certo a postura da mosca Sarcophaga feita sobre a terra que cobria um cadaver de cão, mas a espessura da camada superposta não se comparava í que existe nos enterramentos. Deixo nesse ponto ainda uma interrogação. A deducção do tempo do enterramento pelo numero de gerações é neste caso mais aproveitavel, embora não seja sempre seguro.

Eis ahi tudo quanto aprendi durante 14 annos, já agora feitos, de ensaios, experiencias e observações sobre o assumpto.

Estou convencido de que a fauna cadaverica para ser prestante á $\mathrm{Me}$ dicina Legal é preciso que mesmo naquelles casos que apontei seja o trabalho dado a um entomologista especialisado, tantas são as difficuldades da diagnose. Trata-se em geral de determinar especies pelas larvas, pelas crysalidas ou pupas ou por fragmento do corpo dos adultos. E' um trabalho meticuloso e difficilimo até quando existem, o que não é frequente, bôas descripções entomologicas de cada especie. De mais cumpre conhecer profundamente a biologia e a ecologia dos insectos e dos acarianos. Por isto é preciso que não seja qualquer entomologista, que se não recorra a esses que veem nos insectos um pobre anımal innocente cuja unica utilidade é ser espetado, rọtulado, baptisado, numeradio e guardado em caixinhas. qưe não vê atravez dos pobres animaes a vida, a natureza, a actividade prodigiosa dos instinctos, que consideram toda entomologia lama sciencia de classificação rebarbativa em que as intelligencias se dessecam e esterilisam tanto quanto os pobres insectos de que cuidam. E' preciso saber escolher o especialista, a quem o medico peritito deve recorrer.

Já agora nem mais me animo a pedir-vos perdão do tempo que vos roubei sem piedade e com aquella conhecida inconsciencia com que os estudiosos de um assumpto, alheiados do tempo e das conveniencias torturam horas a fio a paciencia do proximo resignaldo. E' que se o vosso espirito treinado pelo velho habito das aulas que nem sempre attráem, que raramente deliciam e que bem poucas vezes ensinam resistir ao trauma moral desta estopada, fundo, foi talvez o abalo da amarga desillusão que vos trouxe. Poìs será assinu a sciencia, perguntareis comvosco? Tão minguado producto custará tanto esforço, tanta canseira e tão grande tempo? Tão parco rendimento para tamanho dispendio de força e de actividade? 
F de crer estaes neste momento a lastimar. Como vos dilludis meus prezados amigos. Muito differem, é certo, os homens. Uns, mais felizes na confortavel paz dos seus gabinetes de estuados, com a só conselho dos livros predilectos, chegam a conhecimento perfeito do universo e da natureza inteira. Todosı os segredos do Universo são accessiveis ao seu conhecimento eschematizados, devidamente numerados nas prateleiras das suas estantes. Nunca sentiram o anceio de uma duvida, nem tiveram jámais o enllejio da curfiosidade descontente. Teem a convicção facil e a verdade prompta e prestadia, na mão, no bolso ou nos livros. Outros mais humildes, como aquelles operarios dos insectos 'sociaes nunca logram essa suprema ventura da certeza absoluta e inappellavel. As poucas conviç̧ões que nutrem só conseguem haurill-as na evidencia dos factos, com trabalhos e com fadigas que nem sempre compensam o esforço nem satisfazem e curiosidade. Vaciliam a cada instante, duvidam a cada hora, mas em compensação experimentam uma alegria que nunca os outros poderão sentir, a que the concedem essas parcella's diminutas da verdade que conquistam ou que pelo menos julgam conquistar. São ellas a sua alegria, o seu orgulho, clarão maravilhoso que os guia e os fortalece, que os eleva acima das paixões mesquinhas, que os desinteressam das preoccupações subalternas, das victorias immediatas, que thes dão serenidade, contra a nveja que se rão sabe comı e porque nasceu, mas que não perdoa, os ollios que ninguem comprehende porque existem mas que não se saciam nem se cansam, e emquanto fervilha em torno o impressionante fermentar dessas verdadeiras larvas de putrefacção moral, sequiosas e famintaș, tem o individuo a sensação feliciosa de caminhar na vida na companluia imiga do seu sonho satisfeito e da sua consciencia fortalecida por uma alspiração realisada. Nessa atmospheia de recolhimento fructificam melhor a obra do coração e da intelligencias, e conquistareis o destemor para arrostar a lucta aspera e sem mercê em que a alma estraçoada assignala sangrando, tanta vez, um por um, os marcos da jornada. Essa imperccive: alegria interior de deverdes a vós sómente, ao vosso esforço, ao vosso trabalho, á vossa actividade essa diminuta parcella do conhecimento da natureza será sempre comvosco e jorrará de vosisos corações 'quer vos atcrmente a desdita, quer vos exaltem os favores da fortuna.

Si alguma licção, meus amigos, valiosa, podereis colher desta palestra s m pretenções, si algum incitamento ella póde deixar para a vossa vida c. para vossa actividade será justamente esse de trabalhardes pela sciencia brasileira, sem a preoocupação mesquinha da applicação immediata, co utilitarismo grosseiro e esterilisante que é positivamente o mal maior do vosso esforço. Fazendo a sciencia pela sciencia, pelas allegrias que clla concede, pela elevação moral que do seu trato resulta, dominados pelo 
juramento de que todos os esforços em prol do conhecimento dos probiemas do Universo são uteis, por menores que sejam, por estreitos os seus limites, adquiriris uma norma de conducta e uma vantagem immensa sobre os demais, bastando á vassa felicidade as alegrias sem limites, sem parelhas, puras e profundas, que só a sciencia desinteressada voss pode concedier.

Oscar Freire.

(1) Por equivoco typographico a 1." parte deste trabalho, que. era inicio e não continuaçäo, appareceu no numero anterior indicada como continuando.

\section{LABORATORIO DE CHIMICA, MICROSCOPIA} E BIOLOGIA CLINICAS

Analyses em geral - Vaccinotherapia

Dr. Aristides G. Guimarães - Dr. Oscar M. de Barros Ph. ${ }^{\text {co }}$ Mendonça Cortez

RUA DIREITA, $35-1 .^{\circ}-$ Telephone: Central, 5033 Caixa Postal, 1600 